\title{
Hepatic steatosis in patients with HIV-Hepatitis C Virus coinfection: is it associated with antiretroviral therapy and more advanced hepatic fibrosis?

\author{
Sumita Verma*1, Robert D Goldin ${ }^{2}$ and Janice Main ${ }^{1}$
}

Address: ${ }^{1}$ Hepatology Section, Department of Medicine, Imperial College at St Mary's Hospital, London, UK and ${ }^{2}$ Department of Cellular Pathology, Imperial College at St Mary's Hospital, London, UK

Email: Sumita Verma* - s.verma@bsms.ac.uk; Robert D Goldin - r.goldin@imperial.ac.uk; Janice Main - j.main@imperial.ac.uk

* Corresponding author

Published: 15 July 2008

BMC Research Notes 2008, I:46 doi: 10.1 I86/1756-0500-I-46
Received: 26 March 2008

Accepted: 15 July 2008

This article is available from: http://www.biomedcentral.com/I756-0500/I/46

(C) 2008 Verma et al; licensee BioMed Central Ltd.

This is an Open Access article distributed under the terms of the Creative Commons Attribution License (http://creativecommons.org/licenses/by/2.0), which permits unrestricted use, distribution, and reproduction in any medium, provided the original work is properly cited.

\begin{abstract}
Background and aims: Patients with HIV and hepatitis $\mathrm{C}$ virus (HCV) coinfection are at increased risk of developing hepatic steatosis. The aims of this study were to assess the prevalence of steatosis in a cohort with HIV-HCV coinfection, and to determine an association, if any, between steatosis, antiretroviral therapy (ART), and advanced hepatic fibrosis.
\end{abstract}

Patients and methods: HIV-HCV coinfected patients were retrospectively identified from the HIV clinic. ART was classified as none, nucleoside reverse transcriptase inhibitors (NRTIs) only, highly active antiretroviral therapy (HAART) only, and sequential therapy (initial NRTIs followed by HAART). Fibrosis stage and necroinflammation grade were assessed by the modified HAl (Ishak) scoring method. Steatosis was graded as $0-3$.

Results: Sixty patients were identified. The overall prevalence of hepatic steatosis was $58 \%$. Those that received HAART only had a lower prevalence of steatosis (4I\%) compared to those on NRTIs only $(70 \%)$ or sequential therapy (82\%). Independent predictors of hepatic steatosis were absence of HAART only therapy, OR 2.9, $p=0.09$, and presence of cirrhosis, OR 4.6, $p=0.044$. Forty five percent of the patients had advanced fibrosis (fibrosis stage $\geq 3)$. NI grade $(O R I .9, p=0.030)$, and steatosis grade $(O R 3.6, p=0.045)$, were independent predictors of advanced fibrosis.

Conclusion: Hepatic steatosis is associated with more advanced hepatic fibrosis in the HIV-HCV coinfected population. HAART only therapy (rather than NRTIs only or sequential therapy) appears to be associated with a lower prevalence of hepatic steatosis. This may be one of the mechanisms by which HAART could attenuate hepatic fibrosis in such a cohort.

\section{Introduction}

Highly active antiretroviral therapy (HAART) has significantly improved survival in patients with human immunodeficiency virus (HIV) infection [1]. Increasing attention is now being focused on co infection with other viruses like hepatitis C (HCV). Because of similar routes of trans- mission, approximately $25-30 \%$ of patients with HIV are also coinfected with HCV [2]. Factors associated with more advanced hepatic fibrosis in HCV infection include HIV coinfection [3] and hepatic steatosis, (prevalence of $47 \%-79 \%$ ) [4-6]. 
Patients with HIV are also at increased risk of developing hepatic steatosis due to multiple factors including antiretroviral therapy (ART), obesity, hyperglycemia, lipodystrophy, and coinfection with HCV [2,7-11]. In HIV-HCV coinfection prevalence of hepatic steatosis varies between $40-72.1 \%$ [9-13]. In the coinfected population, the association between ART and steatosis, and whether steatosis is associated with advanced fibrosis remains controversial [9-11]. The aims of this study were therefore to assess whether in those with HIV-HCV coinfection

1. Use of ART is associated with hepatic steatosis

2. Hepatic steatosis is an independent predictor of advanced hepatic fibrosis

3. Hepatic steatosis is associated with fibrosis progression in serial liver biopsies

\section{Patients and methods}

The study period was from 1990-2005. Patients with HIVHCV coinfection were identified from the Pathology and HIV database after which, their charts and computerised chemical pathology and histology databases reviewed. To be included in the study the patients had to be

\section{HCV antibody and or HCV PCR (qualitative) positive}

\section{HIV antibody positive}

\section{Have had a liver biopsy.}

The indications for a liver biopsy in most patients were abnormal liver tests. All the liver biopsies had been reviewed by RG who was blinded to the clinical information. The fibrosis stage (0-6) and necroinflammatory (NI) grade (0-18) were assessed by the modified HAI (Ishak) scoring system [14]. Steatosis was graded, (depending on $\%$ of hepatocytes containing fat), into grade $0(<5 \%)$, grade $1(<33 \%)$, grade $2(33 \%-66 \%)$, and grade 3 $(>66 \%)$.

HCV disease duration and fibrosis progression were calculated as before [15]. Lipoatrophy was stated to be present if mentioned in the patient records. Diabetes mellitus (DM) was defined by presence of one or more of the following: fasting blood glucose $>7 \mathrm{mmol} / \mathrm{l}$, being on anti diabetic medications, and/or a note in the patient record stating that there was a history of DM.

Anti-HCV antibody testing, HCV RNA and HIV RNA quantification and HCV genotyping were performed in the hospital virology laboratory using standard commercial kits (Abbott, Bayer, Roche).
Alcohol abuse was defined as either consumption of $>3$ units of alcohol/day (approximately $40 \mathrm{gms} /$ day), and/or a written note in patient records stating that there was a history of alcohol excess. Details of ART were also recorded to assess duration of therapy prior to the liver biopsy. ART was classified as [16].

\section{None \\ 2. NRTIs only}

3. HAART only. Those whose HIV was diagnosed in or after 1996 and were therefore treated with HAART at onset. For the purpose of this study HAART was defined as use of any two nucleoside reverse transcriptase inhibitors (NRTIs) with any protease inhibitor (PI) or non nucleoside reverse transcriptase inhibitors (NNRTI)

4. Sequential therapy: Those whose HIV was diagnosed prior to 1996; hence were initially treated with NRTIs and then converted to HAART after 1996.

Ethnicity was classified (according to the HIV database) into White, Other European and Others.

The following patients were excluded

1. Presence of liver disease of another etiology, e.g. active hepatitis B infection, autoimmune liver disease, genetic hemochromatosis, and cholestatic liver disease

\section{Medical records/clinical data not available}

\section{Statistical Analysis}

Data are presented as mean \pm SD except the HIV and HCV viral load (VL) which are presented as median (range). Differences between continuous variables were compared using the Mann Whitney (U) Test and between categorical variables by the Chi Square and Fischer's Exact Test. Binary logistic regression analysis was performed to assess independent predictors of hepatic steatosis and fibrosis stage $\geq 3$. The statistical software programme used was SPSS version 14 (Chicago, IL)

\section{Results}

From 1990-2005 there were sixty-six patients with HIV who had been coded as having had a liver biopsy for HCV. Six were excluded, and therefore 60 patients were found suitable for the study. Of these sixty patients 52 (87\%) had abnormal transaminases. All were HCV antibody positive, and all but one was HCV RNA (qualitative) positive. Eight patients had undergone more than one biopsy, of whom seven had had two and one three biopsies. 
Table 1 shows data in the whole cohort at the time of the most recent biopsy. The mean age at HIV diagnosis was $33.3 \pm 8.1$ years. Mean duration of HIV prior to biopsy was $6.2 \pm 5.5$ years. At the time of the biopsy, $53(88 \%)$ had a CD 4 count $\geq 200$ and $52 \%$ had undetectable HIV VL. Overall, 12 had received an NNRTI, 9 a PI and 12 had received both. As regards NRTI, 17 had received stavudine (d4T), 13 didanosine (ddI) and 33 zidovudine (AZT). Of the 17 who had received no ART at the time of the biopsy, 16 were long-term non-progressors.

Table I: Data in whole cohort $(n=60)$ at the time of the most recent liver biopsy

\begin{tabular}{|c|c|}
\hline Age at biopsy (yrs) & $39.4 \pm 8.2$ \\
\hline \multicolumn{2}{|l|}{ Ethnicity } \\
\hline White & $24(40 \%)$ \\
\hline Other European & $24(40 \%)$ \\
\hline Others & $12(20 \%)$ \\
\hline Male & $54(90 \%)$ \\
\hline Weight (kg) & $72.3 \pm 10.1$ \\
\hline$>75 \mathrm{~kg}$ & $24(40 \%)$ \\
\hline Diabetes Mellitus & $3(5 \%)$ \\
\hline Lipoatrophy & $5(8 \%)$ \\
\hline \multicolumn{2}{|l|}{ Risk factors for HCV } \\
\hline IDU & $32(53 \%)$ \\
\hline Blood transfusion & $3(5 \%)$ \\
\hline Homosexual & $19(32 \%)$ \\
\hline Heterosexual & $3(5 \%)$ \\
\hline Tattoos/fisting & $3(5 \%)$ \\
\hline Unknown & I (2\%) \\
\hline Alcohol Abuse & $18(30 \%)$ \\
\hline $\mathrm{CD} 4+\left(/ \mathrm{mm}^{3}\right)$ & $450(100-1200)$ \\
\hline HIV VL (copies/ml) & UD (UD-210,955) \\
\hline \multicolumn{2}{|l|}{ Antiretroviral therapy } \\
\hline None & 17 (28\%) \\
\hline NRTI only & $10(17 \%)$ \\
\hline HAART only & $22(37 \%)$ \\
\hline Sequential therapy & II (I8\%) \\
\hline HCV VL (IU/ml)* & $869,299(27 \mid 6-14,975,540)$ \\
\hline HCV genotype I* & $30 / 42(71 \%)$ \\
\hline HCV disease duration (yrs) & $16.4 \pm 8.0$ \\
\hline \multicolumn{2}{|l|}{ Liver Biopsy** } \\
\hline Fibrosis stage & $2.8 \pm 1.7$ \\
\hline $\begin{array}{l}\text { Fibrosis progression rate/yr } \\
\text { (FPR)* }\end{array}$ & $0.21 \pm 0.16$ \\
\hline Cirrhosis & 15 (25\%) \\
\hline Necroinflammatory grade & $3.7 \pm 1.7$ \\
\hline Hepatic steatosis & $35(58 \%)$ \\
\hline
\end{tabular}

*HCV viral load and genotyping unavailable in 16 and 18 patients respectively

*FPR unavailable in 22 patients

** Data in median (range): fibrosis stage 2 (0-6), necroinflammatory grade $3(1-9)$, fibrosis progression rate/yr $0.15(0-0.67)$, steatosis grade I (0-3)

UD: undetectable

Ethnicity: In Other European the country of origin was as follows: Italy $n=8$, Portugal $n=8$, Spain $n=5$, Germany $n=1$, France $n=1$ and Venezuela $n=1$. Others included Brazil $n=3$, Russia $n=3$, Yugoslavia $n=3$, India $n=1$, Iran $n=1$ and Libya $n=1$
Some degree of hepatic steatosis was present in $58 \%$ of the patients, with the majority having grade 1 steatosis (Fig 1 ). Table 2 shows data in those with and without steatosis. Those who received NRTIs only $(70 \%)$ or sequential therapy $(82 \%)$ were more likely to have hepatic steatosis compared to those that received HAART only $(41 \%), \mathrm{p}=0.11$ and 0.64 respectively), (Fig 2). The use of HAART only therapy was protective against development of steatosis (Table 2). The mean steatosis grade in the HAART only group was $0.5 \pm 0.8$. This was lower than that seen in the NRTI only $(1.2 \pm 1.0, p=0.20)$, sequential therapy group $(0.9 \pm 0.5, \mathrm{p}=0.63)$, and no therapy group $(0.6 \pm 0.6)$. Further sub group analysis indicated the prevalence of steatosis as follow: stavudine $(70 \%)$, didanosine $(61 \%)$, zidovudine $(63 \%)$, any PI therapy (62\%), and any NNRTI therapy (58\%).

There was no difference in durations of different forms of ART in those with and without steatosis (Table 2). The overall duration of ART was longer in those with sequential therapy $(94.3 \pm 35.5 \mathrm{mths})$, compared to NRTI only $(22.9 \pm 17.3 \mathrm{mths})$ and HAART only groups $(29.9 \pm 26.5$ $\mathrm{mths}), \mathrm{p}<0.05$. However presence of steatosis was not associated with duration of ART $(50.6 \pm 43.0$ vs. $32.7 \pm$ $30.6 \mathrm{mths})$. Duration of stavudine ( $32.8 \pm 21.7$ vs. $45.8 \pm$ $25.4)$, and didanosine $(24.6 \pm 16.6$ vs. $31.2 \pm 29.7)$ were also no different in those with and without steatosis (p value $=1.0$ and 0.80 respectively). All factors that were significantly associated with steatosis on univariate analysis ( $\mathrm{p} \leq 0.1$ ) (HAART only therapy, sequential therapy, and presence of cirrhosis) were then entered into a stepwise logistic regression model. Independent predictors of hepatic steatosis were absence of HAART only therapy, OR 2.9 (95\% CI 0.84-9.9), $\mathrm{p}=0.09$ and presence of cirrhosis, OR 4.6 (95\% CI 1.0-20.4), $\mathrm{p}=0.044$. Because of the small sample size we could not analyze the association between diabetes mellitus $(n=3)$, genotype $3(n=6)$, lipoatrophy $(n=5)$ and hepatic steatosis.

Table 3 shows data in those with $\geq$ vs. < stage 3 fibrosis. There were no significant differences in serum bilirubin, transaminases and HCV VL (data not shown).

Duration of stavudine $(44.9 \pm 21.5$ vs. $24.8 \pm 20.6)$ and didanosine $(34.0+22.1$ vs. $11.7 \pm 10.4)$ were longer in those with fibrosis stage $\geq 3$, though the differences did not achieve statistical significance ( $\mathrm{p}$ value $=1.0$ and 0.80 respectively). Factors that were significantly associated with fibrosis stage $\geq 3$ on univariate analysis $(\mathrm{p} \leq 0.1)$ (HIV diagnosed before or after 1996, cholestrol/HDL ratio, platelet count, grade of hepatic steatosis, necroinflammatory grade, and CD4 counts at time of the biopsy) were then entered into a step wise logistic regression model. The following were independently associated with advanced fibrosis: grade of necroinflammation (OR 1.9 
Table 2: Data in patients with and without hepatic steatosis

\begin{tabular}{|c|c|c|c|}
\hline & Hepatic steatosis & Hepatic steatosis & $P$ value \\
\hline & Yes & No & \\
\hline & $\mathrm{n}=35$ & $\mathrm{n}=25$ & \\
\hline Age at biopsy (yrs) & $39.0 \pm 8.9$ & $40.0 \pm 7.2$ & ns \\
\hline Age at HIV diagnosis (yrs) & $32.9 \pm 8.9$ & $34.0 \pm 6.8$ & ns \\
\hline Male & $32(9 \mid \%)$ & $22(88 \%)$ & ns \\
\hline ethnicity & $14(40 \%)$ & $9(36 \%)$ & ns \\
\hline Weight $(\mathrm{kg})$ & $74.2 \pm 9.2$ & $69.7 \pm 10.8$ & 0.74 \\
\hline Weight > $75 \mathrm{~kg}$ & $17(48 \%)$ & $7(28 \%)$ & ns \\
\hline Diabetes mellitus & $2(6 \%)$ & I (4\%) & ns \\
\hline Alcohol & $11(31 \%)$ & $7(28 \%)$ & ns \\
\hline \multicolumn{4}{|l|}{ Antiretroviral therapy } \\
\hline No therapy & $10(28 \%)$ & $7(28 \%)$ & ns \\
\hline NRTI & $7(20 \%)$ & $3(12 \%)$ & ns \\
\hline Duration (mths) & $22.3 \pm 18.8$ & $21.7 \pm 12.4$ & ns \\
\hline HAART only & $9(26 \%)$ & $13(52 \%)$ & 0.037 \\
\hline Duration (mths) & $30.4 \pm 27.3$ & $29.5 \pm 27.1$ & ns \\
\hline Sequential & $9(26 \%)$ & $2(8 \%)$ & 0.08 \\
\hline Duration (mths) & $92.8 \pm 37.2$ & 106.0 & ns \\
\hline Received PI & $13(37 \%)$ & $8(32 \%)$ & ns \\
\hline Received NNRTI & 14 (40\%) & $10(40 \%)$ & ns \\
\hline Received stavudine & $12(34 \%)$ & $5(20 \%)$ & ns \\
\hline Received didanosine & $8(23 \%)$ & $5(20 \%)$ & ns \\
\hline Received zidovudine & $21(60 \%)$ & $12(48 \%)$ & ns \\
\hline Time from HIV diagnosis to HAART (mths) & $47.4+38.7$ & $40.4+50.9$ & ns \\
\hline CD4 count (/mm3) & $410(110-1100)$ & $490(100-1200)$ & ns \\
\hline HIV VL (copies/ml) & UD (UD-2 I0955) & 70 (UD-121843) & ns \\
\hline HCV VL $(\mathrm{IU} / \mathrm{ml})$ & $441309(27 \mid 6-769231)$ & $\mid 286755(2945|-| 4975540)$ & ns \\
\hline Non I genotype & $6 / 21(28 \%)$ & $6 / 21(28 \%)$ & ns \\
\hline Cholestrol & $4.3 \pm 1.2$ & $4.1 \pm 1.08$ & ns \\
\hline HDL & $1.1 \pm 0.5$ & $1.1 \pm 0.3$ & ns \\
\hline Triglyceride & $2.2 \pm 2.0$ & $1.5 \pm 0.6$ & ns \\
\hline Cholestrol/HDL ratio & $4.8 \pm 2.2$ & $3.8 \pm 1.0$ & ns \\
\hline Fasting blood glucose & $6.1+6.4$ & $5.1 \pm 0.9$ & ns \\
\hline ALT (IU/L) & $|3|+\mid 49.8$ & $104 \pm 74.6$ & ns \\
\hline Fibrosis stage & $3.0 \pm 1.9$ & $2.5 \pm 1.7$ & ns \\
\hline $\mathrm{NI}$ grade & $3.7 \pm 1.9$ & $3.7+1.7$ & ns \\
\hline Cirrhosis & $12(34 \%)$ & $3(12 \%)$ & 0.049 \\
\hline
\end{tabular}

Normal range for lab values: ALT $<40$ iu/L, Bilirubin $<17$ umol/L, Alkaline phosphates 30-130 iu/L, Albumin 35-4l g/L, Cholestrol <5 mmol/L, triglycerides $<2.30 \mathrm{mmol} / \mathrm{L}, \mathrm{HDL}$ cholesterol $>1.00 \mathrm{mmol} / \mathrm{L}$, Cholestrol/HDL $<5.00 \mathrm{mmol} / \mathrm{L}$, fasting blood glucose $3-5.5 \mathrm{mmol} / \mathrm{L}$ HDL: high density lipoprotein

UD: undetectable

Data on lipids unavailable in 10 patients

(95\% CI 1.1-3.3, p = 0.030), and grade of hepatic steatosis (OR 3.6 (95\% CI 1.0-12.7), p = 0.045). There were 15 patients who had both a necroinflammatory grade $\geq 4$ (mean grade in the whole group) and steatosis. Prevalence of cirrhosis in this group was $40 \%$, compared to $13 \%$ in those without any of these two factors $(p=0.02)$. Fig 3 shows the fibrosis progression rates/year (FPR) in those with and without hepatic steatosis. The FPR was faster in the former though the differences did not achieve statistical significance, probably due to the small sample size.
Of the eight patients with more than one biopsy, the mean interval between the biopsies was $52 \pm 17.9$ months. Five had fibrosis progression $\geq$ one stage of whom $4(80 \%)$ showed evidence of hepatic steatosis in the index biopsy.

\section{Discussion}

This study has shown that $58 \%$ of HIV-HCV coinfected patients (of whom $72 \%$ were on ART) have evidence of hepatic steatosis on liver biopsy, and this is consistent 


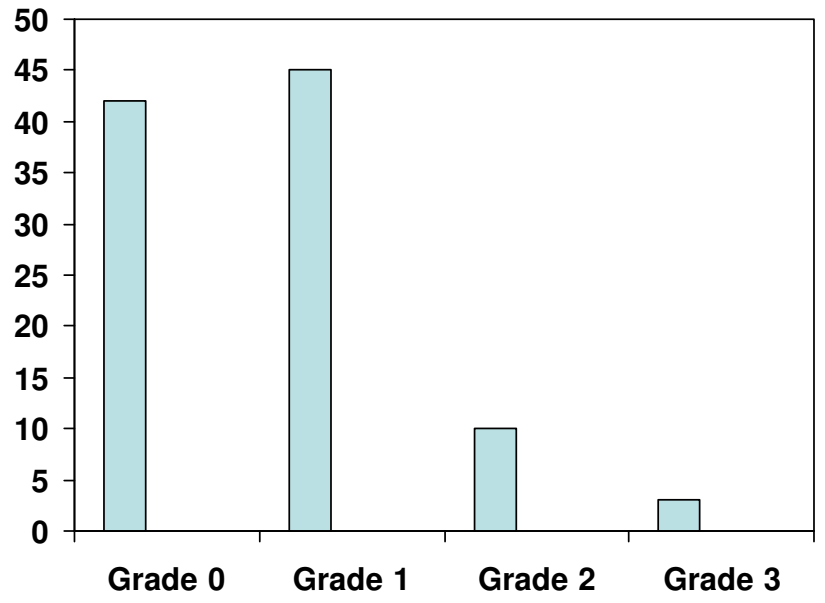

Figure I

The prevalence of hepatic steatosis (in percentage) in HIVHCV coinfected Patients.

with earlier data [9-11]. Those who had received an NRTI, either alone, or as part of sequential therapy were twice as likely to have steatosis $(70 \%-82 \%)$ compared to those who had received HAART only therapy (41\%). Independent predictors of hepatic steatosis were absence of HAART only therapy, and presence of cirrhosis. Neither PI or NRTI therapy was independently associated with steatosis. 45\% of patients had advanced fibrosis and both grade of stetaosis and NI were independent predictors of advanced fibrosis. In the subgroup with $>1$ biopsy, $80 \%$ of those

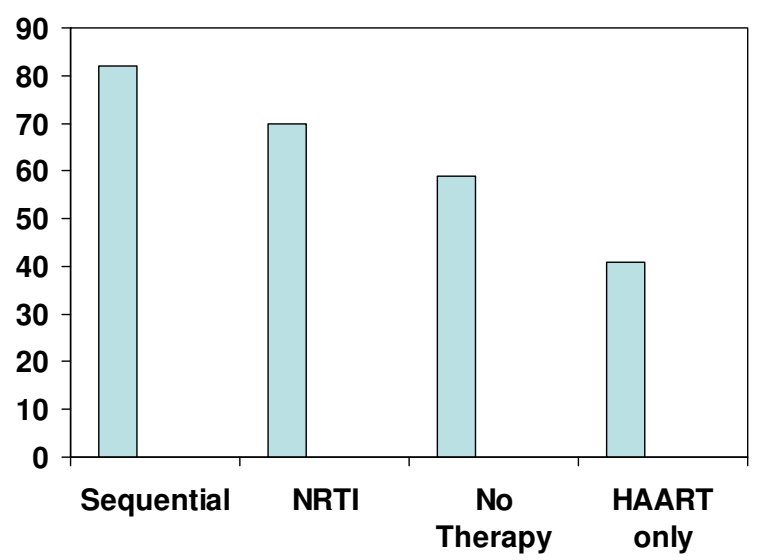

Figure 2

Prevalence of hepatic steatosis (in percentage) depending on type of therapy received. Number of patients with steatosis in the 4 groups was as follows: Sequential 9/II, NRTI 7/I0, No therapy 10/17 and HAART only 9/22. HAART only vs NRTIs only, $p=0.1$ I. HAART only vs sequential therapy, $\mathrm{P}=0.064$. with fibrosis progression had steatosis on the index biopsy.

The lowest prevalence of hepatic steatosis was observed in the HAART only group. Furthermore, the duration between HIV diagnosis and HAART initiation was longer for those with steatosis ( 47.4 vs. 40.4 months). This suggests that receiving HAART early, may in some way be protective against development of subsequent hepatic steatosis. Prior authors have also found a lower prevalence of hepatic steatosis with certain antiretroviral drugs (NNRTI) [1].

So how do we explain this negative association between HAART and hepatic steatosis? It may be partly related to the fact that NNRTIs (especially nevirapine) do not result in insulin resistance and may also be associated with elevations in high density lipoproteins (HDL) [17]. Secondly, HAART has been known to attenuate hepatic NI in coinfected patients $[16,18]$ and there may in fact be an association between NI and hepatic steatosis. This could be because the HCV core protein leads to oxidative stress [19] and hepatic steatosis could result from the inflammation associated with this oxidative stress [20]. One could therefore speculate that appropriately initiated HAART could attenuate hepatic NI (either directly or via immune restoration induced changes in inflammatory cytokines) $[21,22]$, which in turn may reduce hepatic steatosis.

Steatosis has been independently associated with advanced fibrosis in HCV monoinfected patients [6,23] though this remains controversial in HIV-HCV subjects [9-11]. In this study, those with advanced hepatic fibrosis had a significantly higher grade of hepatic steatosis compared to those with less severe hepatic fibrosis, (consistent with Sulkowski et al's data). In fact in our study $80 \%$ of patients with fibrosis progression had hepatic steatosis in the index biopsy. Also, a recent study has observed higher prevalence of hepatic steatosis in HIV-HCV coinfected patients compared with HCV monoinfected subjects (72.1\% vs. 52\%) [14]. Therefore one of the factors contributing to the accelerated fibrosis progression in HIVHCV coinfected patients could be the increased prevalence of hepatic steatosis.

The effects of HAART on liver fibrosis in HIV-HCV coinfected patients remain controversial. Recent data however, do indicate that HAART may attenuate hepatic fibrosis in this cohort especially if patients receive HAART (rather than NRTI or sequential therapy) at onset, and if therapy is associated with successful viral suppression $[16,24]$. Data from this study further corroborates this hypothesis as $70 \%$ of those with fibrosis stage $<3$ had their HIV diagnosed in or after 1996, indicating they were more likely to receive HAART at onset. The underlying mechanism/s 
Table 3: Data in patients with fibrosis stage $\geq$ vs. $<3$

\begin{tabular}{|c|c|c|c|}
\hline & $\begin{array}{l}\text { Fibrosis stage } \geq 3 \\
\mathrm{n}=27\end{array}$ & $\begin{array}{l}\text { Fibrosis stage }<3 \\
\mathrm{n}=33\end{array}$ & $P$ value \\
\hline Age at biopsy (yrs) & $40.6 \pm 8.7$ & $38.3 \pm 7.8$ & ns \\
\hline Age exposed to HCV (yrs) & $20.3 \pm 11.0$ & $24.4 \pm 7.2$ & ns \\
\hline Age at HIV diagnosis (yrs) & $33.6 \pm 9.6$ & $33.1 \pm 6.7$ & ns \\
\hline HIV diagnosed in or after 1996 & II (4I\%) & $23(70 \%)$ & 0.023 \\
\hline White & $8(30 \%)$ & 15 (45\%) & ns \\
\hline Alcohol & $6(22 \%)$ & $12(36 \%)$ & ns \\
\hline Diabetes Mellitus & $\mathrm{I}(4 \%)$ & $2(6 \%)$ & ns \\
\hline Weight & $70.7 \pm 10.0$ & $73.5 \pm 10.2$ & ns \\
\hline Weight $\geq 75 \mathrm{Kg}$ & $\mathrm{II}(4 \mid \%)$ & $13(39 \%)$ & \\
\hline Cholestrol & $4.5 \pm 1.3$ & $4.0 \pm 1.0$ & ns \\
\hline Triglycerides (TG) & $2.1 \pm 1.8$ & $1.8 \pm 1.5$ & ns \\
\hline Cholestrol/TG ratio & $5.0 \pm 2.2$ & $3.8 \pm 1.3$ & 0.02 \\
\hline Platelet count $\left(/ \mathrm{mm}^{3}\right)$ & $163 \pm 65.5$ & $228 \pm 66.8$ & 0.001 \\
\hline \multicolumn{4}{|l|}{ Therapy received } \\
\hline None & $5(18 \%)$ & $12(36 \%)$ & Ns \\
\hline NRTI & $4(15 \%)$ & $6(18 \%)$ & Ns \\
\hline Duration & $11.2 \pm 8.4$ & $29.3 \pm 17.1$ & 0.16 \\
\hline Only HAART & II (4I\%) & II (33\%) & Ns \\
\hline Duration & $29.5 \pm 26.5$ & $30.4 \pm 27.9$ & Ns \\
\hline Sequential & $7(26 \%)$ & $4(12 \%)$ & Ns \\
\hline Duration & $105 \pm 23.3$ & $77.5 \pm 47.3$ & 0.39 \\
\hline Steatosis & $18(67 \%)$ & $17(5 \mid \%)$ & Ns \\
\hline Steatosis grade & $1.0 \pm 0.9$ & $0.5 \pm 0.5$ & 0.028 \\
\hline Necroinflammatory grade & $4.4 \pm 1.9$ & $3.1 \pm 1.3$ & 0.007 \\
\hline CD4 count $\left(/ \mathrm{mm}^{3}\right)$ & $370(130-1100)$ & $510(100-1200)$ & 0.06 \\
\hline HIV VL (copies/ml) & UD (UD-2 I0955) & 28.5 (UD-59540) & Ns \\
\hline
\end{tabular}

UD: undetectable

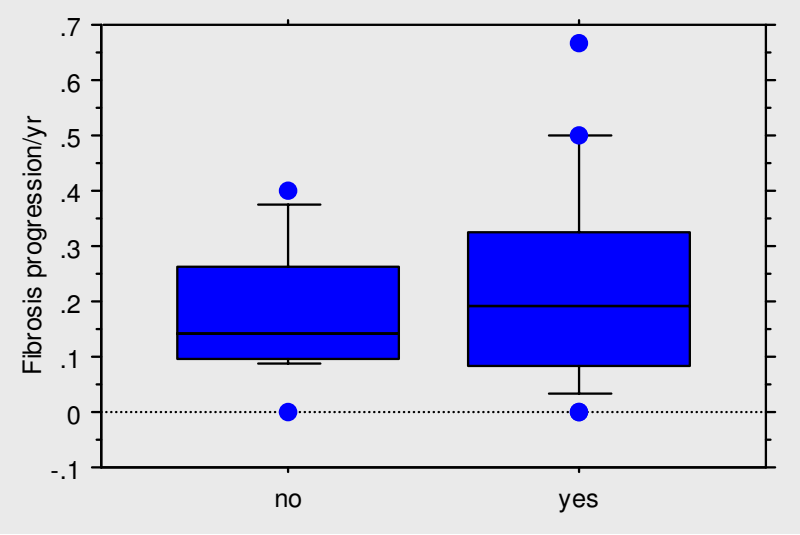

Figure 3

Box plot showing fibrosis progression rates/year in those with (yes) and without (no) hepatic steatosis. responsible for this slower fibrosis progression associated with HAART remain speculative, but could be related to immune restoration induced changes in pro inflammatory and profibrogenic cytokines, a direct effect of HAART on liver fibrosis $[21,25,26]$, or as indicated in this study, the relatively lower prevalence of steatosis (Fig 4).

We however accept the limitations of this study, including its retrospective design, and the small sample size of the coinfected cohort. In addition liver biopsies were performed in only carefully selected patients. Though this clearly resulted in a selection bias, such a bias is true for most studies in this area, and in our opinion is unavoidable.

In conclusion despite a low prevalence of obesity and DM, $58 \%$ of HIV-HCV coinfected patients have evidence of hepatic steatosis histologically. Absence of HAART only therapy was independently associated with steatosis in this study. The presence of hepatic steatosis was also associated with more advanced hepatic fibrosis in the coinfected cohort. The comparatively lower prevalence of hepatic steatosis seen in those that receive HAART only 


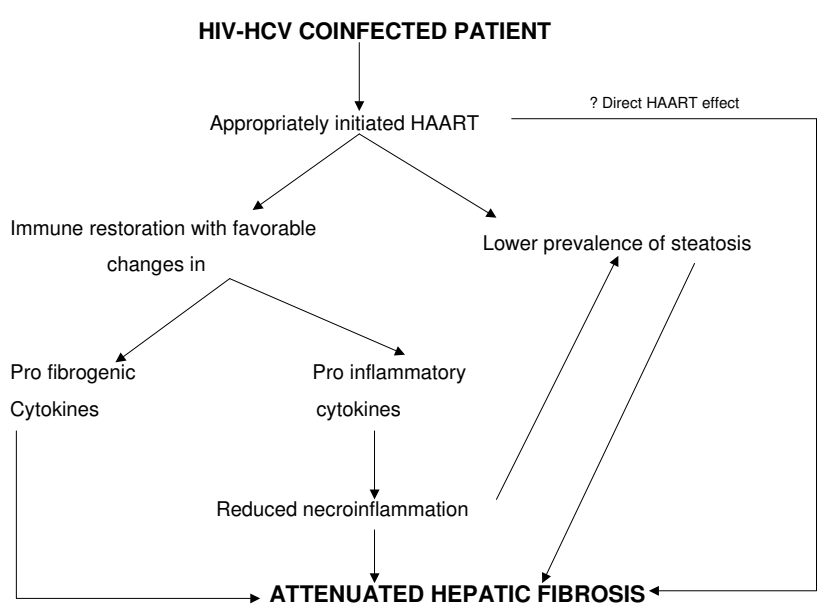

\section{Figure 4}

Proposed mechanism/s for attenuation of hepatic fibrosis observed with HAART in HIV-HCV coinfected subjects.

(rather than NRTIs only or sequential therapy) may contribute to the attenuated hepatic fibrosis that has been observed with this therapy $[17,22]$.

\section{Competing interests}

The authors declare that they have no competing interests.

\section{Authors' contributions}

SV participated in the study design and was responsible for data collection, statistical analysis and drafting of the manuscript. RG performed the histological analysis and contributed to drafting of the manuscript. JM conceived of the study and contributed to drafting of the manuscript. All authors read and approved the final manuscript.

\section{References}

I. Palella FJ Jr, Delaney KM, Moorman AC, Loveless MO, Fuhrer J, Satten GA, Aschman DJ, Holmberg SD: Declining morbidity among patients with advanced human immunodeficiency virus infection. N Engl J Med 1998, 338(I 3):853-60.

2. Sherman KE, Rouster SD, Chung RT, Rajicic N: Hepatitis C Virus prevalence among patients infected with Human Immunodeficiency Virus: a cross-sectional analysis of the US adult AIDS Clinical Trials Group. Clin Infect Dis 2002, 34(6):83 I-7.

3. Graham CS, Baden LR, Yu E, Mrus JM, Carnie J, Heeren T, Koziel MJ: Influence of human immunodeficiency virus infection on the course of hepatitis c virus infection: a meta-analysis. Clin Infect Dis 2001, 33:562-9.

4. Hourigan LF, Macdonald GA, Purdie D, Whitehall VH, Shorthouse C, Clouston A, Powell EE: Fibrosis in chronic hepatitis C correlates significantly with body mass index and steatosis. Hepatol 1999, 29(4): 1215-9.

5. Verma S, Bonacini M, Govindarajan S, Kanel G, Lindsay K, Redeker A: Hispanic ethnicity is associated with an aggressive course of chronic hepatitis $\mathbf{C}$ infection: role of patient demographics, hepatic necroinflammation and steatosis. Am J Gastroenterol 2006, I01:1817-1823.

6. Adinolfi LE, Gambardella M, Andreana A, Tripodi MF, Utili R, Ruggiero $G$ : Steatosis accelerates the progression of liver damage of chronic hepatitis $C$ patients and correlates with specific
HCV genotype and visceral obesity. Hepatol 200I, 33(6): I358-64.

7. Brinkman K, ter Hofstede HJ, Burger DM, Smeitink JA, Koopmans PP: Adverse effects of reverse transcriptase inhibitors: mitochondrial toxicity as common pathway. AIDS 1998, I 2( I 4): I735-44. Review

8. Mehta SH, Moore RD, Thomas DL, Chaisson RE, Sulkowski MS: The effect of HAART and HCV infection on the development of hyperglycemia among HIV-infected persons. J Acquir Immune Defic Syndr 2003, 33(5):577-84.

9. Sulkowski MS, Mehta SH, Torbenson M, Afdhal NH, Mirel L, Moore RD, Thomas DL: Hepatic steatosis and antiretroviral drug use among adults coinfected with HIV and hepatitis $C$ virus. AIDS 2005, I9(6):585-9.

10. Monto A, Dove LM, Bostrom A, Kakar S, Tien PC, Wright TL: Hepatic steatosis in HIV/hepatitis $C$ coinfection: prevalence and significance compared with hepatitis $\mathbf{C}$ monoinfection. Hepatol 2005, 42(2):310-6.

I I. Marks KM, Petrovic LM, Talal AH, Murray MP, Gulick RM, Glesby MJ: Histological Findings and Clinical Characteristics Associated with Hepatic Steatosis in Patients Coinfected with HIV and Hepatitis C Virus. J Infect Dis 2005, I 92(I I): I 943-9.

12. Bani-Sadr F, Carrat F, Bedossa P, Piroth L, Cacoub P, Perronne C, Degott C, Pol and ANRS HC02-Ribavic Study team: Hepatic stetaosis in HIV-HCV coinfected patients: analysis of risk factors. AIDS 2006, 20(4):525-3I.

13. Gaslightwala I, Bini EJ: Impact of human immunodeficiency virus infection on the prevalence and severity of steatosis in patients with chronic hepatitis $\mathbf{C}$ virus infection. I Hepatol 2006, 44(6): 1026-32.

14. Ishak K, Baptista A, Biachi L, Callea F, De Groote J, Gudat F, Denk H: Histological grading and staging of chronic hepatitis. J Hepatol 1995, 22:696-9.

15. Poynard T, Bedossa P, Opolon P: Natural history of liver fibrosis progression in patients with chronic hepatitis $C$. The OBSVIRC, METAVIR, CLINIVIR, and DOSVIRC groups. Lancet 349(9055):825-32. 1997 Mar 22

16. Verma S, Wang CH, Govindarajan S, Kanel G, Squires K, Bonacini M: Do type and duration of antiretroviral therapy attenuate liver fibrosis in HIV-hepatitis $\mathbf{C}$ virus-coinfected patients? Clin Infect Dis 2006, 42(2):262-70.

17. van Leth F, Phanuphak P, Stroes E, Gazzard B, Cahn P, Raffi F, Wood R, Bloch M, Katlama C, Kastelein JJ, Schechter M, Murphy RL, Horban A, Hall DB, Lange JM, Reiss P: Nevirapine and efavirenz elicit different changes in lipid profiles in antiretroviral-therapynaive patients infected with HIV-I. PLoS Med 2004:el9.

18. Mehta SH, Thomas DL, Torbenson M, Brinkley S, Mirel L, Chaisson RE, Moore RD, Sulkowski MS: The effect of antiretroviral therapy on liver disease among adults with HIV and hepatitis C coinfection. Hepatol 2005, 4 I (I): |23-3I.

19. Okuda M, Li K, Beard MR, Showalter LA, Scholle F, Lemon SM, Weinman SA: Mitochondrial injury, oxidative stress, and antioxidant gene expression are induced by hepatitis $C$ virus core protein. Gastroenterol 2002, I22(2):366-75.

20. Day CP, James OF: Steatohepatitis: a tale of two "hits"? Gastroenterol 1998, I | 4(4):842-5.

21. Verma S: HAART attenuates Liver Fibrosis in patients with HIV/HCV Coinfection: Fact or Fiction? J Antimicrob Chemother 2006, 58:496-50I.

22. Graham CS, Curry M, He Q, Afdhal N, Nunes D, Fleming C, Horsburgh R, Craven D, Sherman KE, Koziel MJ: Comparison of HCVspecific intrahepatic CD4+ T cells in HIV/HCV versus HCV. Hepatol 2004, 40(I): I 25-32.

23. Leandro G, Mangia A, Hui J, Fabris P, Rubbia-Brandt L, Colloredo G, Adinolfi LE, Asselah T, Jonsson JR, Smedile A, Terrault N, Pazienza V, Giordani MT, Giostra E, Sonzogni A, Ruggiero G, Marcellin P, Powell EE, George J, Negro F, HCV Meta-Analysis (on) Individual Patients' Data Study Group: Relationship between steatosis, inflammation, and fibrosis in chronic hepatitis C: a meta-analysis of individual patient data. Gastroenterol 2006, I30(6): | 636-42.

24. Brau N, Salvatore M, Rios-Bedoya CF, et al.: For The Puerto RicoNew York Hepatitis Study Group. Slower fibrosis progression in HIV/HCV-coinfected patients with successful HIV suppression using antiretroviral therapy. J Hepatol 2006, 44(I):47-55. 
25. Puoti M, Bonacini M, Spinetti A, Putzolu V, Govindarajan S, Zaltron S, Favret M, Callea F, Gargiulo F, Donato F, Carosi G, HIV-HCV Coinfection Study Group: Liver fibrosis progression is related to CD4 cell depletion in patients coinfected with hepatitis C virus and immunodeficiency virus. Infect Dis 200I, I83:I34-I37.

26. Benhamou Y, Di Martino V, Bochet M, Colombet G, Thibault V, Liou A, Katlama C, Poynard T, MultivirC Group: Factors affecting liver fibrosis in human immunodeficiency virus-and hepatitis $C$ virus-coinfected patients: impact of protease inhibitor therapy. Hepatol 200I, 34(2):283-7.

Publish with Bio Med Central and every scientist can read your work free of charge

"BioMed Central will be the most significant development for disseminating the results of biomedical research in our lifetime. "

Sir Paul Nurse, Cancer Research UK

Your research papers will be:

- available free of charge to the entire biomedical community

- peer reviewed and published immediately upon acceptance

- cited in PubMed and archived on PubMed Central

- yours - you keep the copyright

Submit your manuscript here:

http://www.biomedcentral.com/info/publishing_adv.asp 